\title{
Confidential Inquiries into Cot Deaths in British Forces Germany
}

\section{Lt Col SAStJ Miller}

MSc, MFPHM, RAMC

Medical Branch, Headquarters United Kingdom Land Forces

SUMMARY: Confidential inquiries into cases of cot death in British Forces Germany were introduced in 1990. The information which has been collected so far suggests that the current attention to the position in which a baby is placed in a cot, the prevention of overheating and the avoidance of cigarette smoke, is not misplaced. Despite the considerable reduction in the cot death rate which has occurred in British Forces Germany since 1990 it is recommended that confidential inquiries should be continued so that possible opportunities to further reduce the risks are not missed.

\section{Introduction}

In July 1990 a confidential questionnaire was introduced in British Forces Germany to obtain more epidemiological information about each sudden infant death for which no cause was found at post mortem examination. Such infant deaths are colloquially known as cot deaths but are more accurately described as deaths due to Sudden Infant Death Syndrome or SIDS (1).

Although the infant mortality as a whole in British Forces Germany compared favourably with the national rate for civilians of all social classes in England and Wales the SIDS rate was relatively high at that time. In fact the SIDS rate for British Forces Germany for the three years (1987-1989) immediately preceding the decision to introduce a confidential questionnaire had been 3.9 per 1000 live births compared with a national rate in England and Wales of less than 2 per 1000 live births (2).

This was the result of 47 cot deaths being attributed to SIDS and it was therefore considered essential to focus attention on the problem and to try to discover whether there were any appropriate preventive measures which could be taken. It should be pointed out, however, that if facilities had existed for more specialised post mortem examinations to be carried out it is likely that a cause of death would have been detected in some cases. This would have made the SIDS rate for British Forces Germany lower than it actually appeared to be.

Previous examination of the sudden infant deaths which had occurred in British Forces Germany during the period 1982 to 1986 , using information collected from post mortem reports, had shown that there was no significant difference from patterns observed in the civilian population in respect of the age and sex of the infant, the birth weight, the age of the mother, and the season (3). However, post mortem reports provide only limited epidemiological information and it was considered important to obtain more details on each tragic case through the introduction of some kind of confidential inquiry. This conclusion was in accordance with the government response to the recommendations of the report of the Social Services Committee on perinatal, neonatal and infant mortality which had recently been published (4).

After much deliberation it was decided that a confidential questionnaire in two parts, one part to be completed by the doctor involved in the case and the other to be completed by the investigating police officer, would comprise the least intimidating form of inquiry. The information which was to be obtained was intended to supplement what was already available from post mortem reports. The part of the questionnaire which was to be completed by the doctor sought medical information? concerning the pregnancy, the delivery, the neonatal period, and the 48 hours immediately preceding death. The part of the questionnaire for the investigating officero to complete sought information which related to aspects of parenting such as the amount of clothing and bedding used, the type of cot mattress, whether the window was open or closed, and the position of the baby in the cot.

Most of these questions were prompted by concern at? that time about certain risk factors which were considered to be significantly associated with SIDS as a result of various research studies $(5,6,7)$. These risk factors do not cause cot deaths but they appear to be associated to such an extent that when they are deliberately avoided the incidence of cot death falls (8). In November 1991, nearly eighteen months after the questionnaire was introduced, the Department of Health decided that there was sufficient evidence to issue a circular letter giving advice on the subject. It advised that the risk of cot death would be reduced if a baby was placed on its side or back rather than on its front, if it was not exposed to cigarette smoke and if overheating was avoided.

\section{Method}

The questionnaire was introduced on 5 July 1990 by means of a Medical Administrative and Technical Instruction requiring its completion by a doctor in respect of any cot death occurring in British Forces Germany. It was also issued to all branches of the Special Investigation Branch (SIB) for completion by SIB officers involved in the investigation of a cot death. The questionnaire was to be returned to the SO1 Preventive Medicine at Headquarters, British Army of the Rhine. 
Unfortunately it was not possible to introduce a standardised post mortem format at the same time. A standardised approach to the post mortem examination of cot deaths had been recommended by a paediatric pathologist but it included tests which were beyond the resources of the pathology departments at the military hospitals in British Forces Germany (9).

\section{Results}

By 31 December 1993 there had been 14 cot deaths since the questionnaire had been introduced. The SIB returned completed questionnaires for 12 of these cases and 10 were received from general practitioners. The results obtained are summarised in Table 1 and from the information collected on this small number of cases the following observations can be made.

Table 1.

hyaline membrane disease and another baby h⿸广ष्क suffered pneumonia two weeks before death.

Three babies out of nine were described as havifg been sufficiently unwell during the 48 hours precediffg death for medical advice to have been sought. Two $\mathrm{Ff}$ these cases involved upper respiratory tract infectionts and medical advice was given without the baby beigg examined by a doctor. In the third case the baby wiF examined by a doctor and a diagnosis of colic was mafe.

Nine of the babies died in their cots, two in prams aad one in bed with the parents. The amount of clothing and bedding did not seem excessive in any of the cases 1 (xt in at least 10 instances the window was closed, which $\overrightarrow{i s}$ perhaps suggestive of a lack of awareness on the partof the parents regarding the need to avoid overheating.

Summary of information obtained from the questionnaires.

\begin{tabular}{|c|c|c|c|c|c|c|c|c|c|c|c|c|c|}
\hline Case number & 1 & 2 & 3 & 4 & 5 & 6 & 7 & 8 & 9 & 10 & 11 & 12 & $\overrightarrow{0}$ \\
\hline Sex of infant & $\mathrm{F}$ & $\mathrm{M}$ & $\mathrm{M}$ & $\mathrm{M}$ & $\mathrm{F}$ & M & $\mathrm{M}$ & $\mathrm{M}$ & $\mathrm{F}$ & $M$ & $\mathrm{M}$ & $\mathrm{F}$ & $M: F \quad 8: \sqrt{6}$ \\
\hline Age of infant (months) & 4 & 5 & 5 & 2 & 2 & 10 & 3 & 5 & 1 & 7 & 2 & $1 / 2$ & mean $3.0^{\circ}$ \\
\hline Month of death & Aug & Nov & Nov & Dec & $\overline{\mathrm{Dec}}$ & Jan & Jan & May & Aug & Feb & Sep & May & 3 \\
\hline Gestation (weeks) & 30 & - & 29 & 40 & 40 & - & 37 & - & 40 & 40 & 39 & 41 & \\
\hline Birth weight (kgs) & 1.3 & 2.7 & - & 4.1 & 3.3 & - & 4.0 & - & 2.7 & - & 3.6 & 3.8 & बे \\
\hline Twin pregnancy (Yes/No) & $\mathrm{Y}$ & $\mathrm{N}$ & $\mathrm{N}$ & $\mathrm{N}$ & $\mathrm{N}$ & - & $\mathrm{N}$ & - & $\mathrm{N}$ & $\mathrm{N}$ & $\mathrm{N}$ & $\mathrm{N}$ & \\
\hline Age of mother & 21 & 26 & 21 & 23 & 23 & - & 28 & - & 24 & 26 & 26 & - & mean 84 \\
\hline Maternal smoking (Yes/No) & $Y$ & - & - & $\mathrm{N}$ & $\mathrm{Y}$ & $\mathrm{N}$ & $\mathrm{N}$ & - & $\mathrm{N}$ & $\bar{Y}$ & $\mathrm{Y}$ & $\mathrm{Y}$ & $5 / 9 \lesseqgtr$ \\
\hline First baby (Yes/No) & $\mathrm{Y}$ & $\mathrm{N}$ & $\mathrm{N}$ & $\mathrm{N}$ & $\mathrm{Y}$ & - & $\mathrm{Y}$ & - & $\mathrm{N}$ & $\mathrm{Y}$ & $\mathrm{N}$ & $\mathrm{N}$ & $4 / 10 \stackrel{7}{?}$ \\
\hline Father at home (Yes/No) & $\mathrm{Y}$ & $\mathrm{Y}$ & $\mathrm{Y}$ & $\mathrm{N}$ & $\mathrm{N}$ & $\mathrm{N}$ & $\mathrm{N}$ & $\mathrm{Y}$ & $\mathrm{Y}$ & $\bar{Y}$ & $Y$ & $\bar{Y}$ & $8 / 1 \overline{2}$ \\
\hline $\begin{array}{l}\text { Where found } \\
\text { (pram/cot/bed) }\end{array}$ & Cot & $\operatorname{Cot}$ & $\operatorname{Cot}$ & $\operatorname{Pr}$ & $\operatorname{Cot}$ & $\operatorname{Cot}$ & $\operatorname{Cot}$ & $\operatorname{Cot}$ & $\operatorname{Cot}$ & Bed & $\operatorname{Pr}$ & $\mathrm{Cot}$ & \\
\hline Position (prone/supine) & - & - & $\mathrm{P}$ & $\mathrm{P}$ & $\mathrm{P}$ & $\mathrm{P}$ & $\mathrm{S}$ & $\mathrm{P}$ & $\mathrm{S}$ & - & $P$ & $\mathrm{P}$ & P:S 7:2 \\
\hline Window closed & - & $Y$ & $\mathrm{Y}$ & $\mathrm{Y}$ & $\bar{Y}$ & $Y$ & $\mathrm{Y}$ & $\mathrm{Y}$ & - & $\mathrm{Y}$ & $\mathrm{Y}$ & $\mathrm{Y}$ & $10 / 10$ 吾 \\
\hline Duvet (Yes/No) & - & $\mathrm{N}$ & $\mathrm{N}$ & $\mathrm{N}$ & - & $\mathrm{N}$ & $\mathrm{Y}$ & $\mathrm{Y}$ & $\mathrm{N}$ & $\mathrm{N}$ & $\mathrm{N}$ & $\mathrm{N}$ & $\widehat{3}$ \\
\hline Quilt (Yes/No) & - & $\mathrm{Y}$ & $\mathrm{N}$ & $\mathrm{Y}$ & - & $\mathrm{Y}$ & $\mathrm{N}$ & $\mathrm{N}$ & $\mathrm{Y}$ & $\mathrm{Y}$ & $\mathrm{N}$ & $\mathrm{N}$ & 言 \\
\hline Blanket (Yes/No) & - & $\mathrm{N}$ & $\mathrm{Y}$ & $\mathrm{N}$ & - & $\mathrm{N}$ & $\mathrm{N}$ & $\mathrm{Y}$ & $\mathrm{N}$ & $\mathrm{N}$ & $\mathrm{Y}$ & $\mathrm{N}$ & $\overrightarrow{7}$ \\
\hline $\begin{array}{l}\text { Unwell during previous } \\
48 \text { hours (Yes/No) }\end{array}$ & $N$ & $\mathrm{Y}$ & - & $\mathrm{N}$ & $\mathrm{N}$ & - & $\mathrm{Y}$ & $\mathrm{N}$ & - & $\mathrm{N}$ & $\mathrm{N}$ & $\mathrm{Y}$ & $3 / 9$ \\
\hline
\end{tabular}

The mean age of the infants at the time of death was 3.9 months. Only two of the babies had been born prematurely and one of these was from a twin pregnancy.

The mean age of the mother, for the nine cases where this was given, was 24.2 years. Whether or not the mother had smoked in pregnancy was recorded on nine questionnaires. Five of these nine mothers had done so. The mother was a first time parent in four cases out of ten.

Two babies were noted to have had a significant past medical history. One of the premature babies had suffered
In a high proportion of cases, seven out of nine 8 which this information was recorded, the dead bades were found lying in the prone position. With the exception of the baby aged ten months who was odd enough to have been able to roll over independently th finding suggests that these babies had been placed in prone position to sleep.

Finally, in four cases the father was absent from the home at the time of the death. In two of these cases tisis was due to service in the Gulf War. 


\section{Discussion}

The results of such a small study have to be interpreted with considerable caution but the epidemiological patterns seen in this limited number of cases do appear similar to those observed in the civilian population (10). Perhaps the most interesting findings concern the high proportion of cases where the dead baby was in the prone position, where the window was closed, or where the mother smoked in pregnancy.

No conclusions can be drawn about the significance of these observations without either having a control group or at least some idea of the parenting habits of the community in which these deaths occurred. Nevertheless, considering the importance that is now being attached to the position in which the baby is placed in its cot, to the prevention of overheating and to the avoidance of cigarette smoke, the findings are at the very least salutary.

As a result a major study has been initiated into parenting habits in the Service comunity in British Forces Germany and a questionnaire is being completed by health visitors at the time of first contact with the mothers of all newborn babies to gather information on those factors which are believed to have some influence on the incidence of cot death. It is hoped that the results will show where health education efforts need to be concentrated in the future. At the same time it is considered that the need to fill in the questionnaire will provide the health visitor with an opportunity to reinforce current advice to parents on how to reduce the risk of cot death.

Since 1990 there has in fact been a sharp reduction in the incidence of cot deaths in British Forces Germany. During the last four years (1990-1993 inclusive) there have been 25 cases attributed to SIDS. This gives a rate of 1.9 per 1000 live births for the period which is much closer to the national rate for all social classes in England and Wales than previously.

Despite this satisfactory downward trend cot death remains an important topic for study within the military community. So long as cases occur it will be necessary to gather as much information as possible on these possibly preventable tragedies and some form of confidential inquiry will need to continue.

\section{Acknowledgements}

The author would like to thank the Medical Branch at Headquarters United Kingdom Support Command (Germany) and all the primary health care team members and SIB staff who provided the information for this study.

\section{REFERENCES}

1. Bergman AB, Beckwith JB, Ray CC. Sudden infant death syndrome. Seattle: University of Washington Press, 1970.

2. Office of Population Censuses and Surveys (OPCS) Monitor.

3. Miller SAStJ. MFCM Thesis 1989.

4. Chalmers I. Inquiry into stillbirths and infant deaths. Br Med J 1989; 299: 339-340.

5. Dwyer T, Ponsonby AL, Newman NM, Gibbons L E. Prospective cohort study of prone sleeping and sudden infant death syndrome. Lancet 1991; 337: 1244-1247.

6. Fleming PJ, Gilbert R, Azaz Y, et al. Interaction between bedding and sleeping position in the suddent infant death syndrome: a population-based case control study. Br Med J 1990; 301: 85-89.

7. Hagland B, CNattingius S. Cigarette smoking as risk factor for sudden infant death syndrome: a popu lation-based study. Am J Public Health 1990; 808 29-32.

8. Department of Health. Report of the Chief Medica Officer's Expert Group on the sleeping position of infants and cot death. London: HMSO, 1993.

9. Wigglesworth JS, Keeling JW, Rushton DI, et al. Pathological investigations in cases of sudden infant dealth. $J$ Clin Pathol 1987; 40: 1481-1483.

10. Golding J, Limerick S, MacFarlane A. Sudden infant deaths. Patterns, puzzles and problems. Somerset, England: Open Books Publishing Ltd, 1985. 